EXTENDED REPORT

\title{
Autoantibody profiling as early diagnostic and prognostic tool for rheumatoid arthritis
}

\author{
V P K Nell, K P Machold, T A Stamm, G Eberl, H Heinzl, M Uffmann, J S Smolen, \\ G Steiner
}

See end of article for authors' affiliations

\section{Correspondence to:} Dr G Steiner, Department of Rheumatology, Internal Medicine III, Medical University of Vienna, Waehringer Guertel 1820, A-1090 Austria; guenter.steiner@ meduniwien.ac.at

Accepted 3 May 2005 Published Online First 5 May 2005

Background: Early treatment prevents progression of joint damage in rheumatoid arthritis (RA), but diagnosis in early disease is impeded by lack of appropriate diagnostic criteria.

Objective: To study the value of rheumatoid factor (RF), anti-cyclic citrullinated peptide autoantibodies (anti-CCP), and anti-RA33 autoantibodies for diagnosis of RA and prediction of outcome in patients with very early arthritis.

Methods: The prospective follow up inception cohort included 200 patients with very early ( $<3$ months) inflammatory joint disease. Autoantibodies were measured at baseline and analysed in a tree based model which aimed at determining the added diagnostic value of testing for anti-CCP and anti-RA33 as compared with RF alone.

Results: RA was diagnosed in 102 patients, while 98 developed other inflammatory arthropathies. Receiver operator curve analysis showed an optimum cut off level for RF at $50 \mathrm{U} / \mathrm{ml}$, above which antiCCP and anti-RA33 had no additional diagnostic value. Remarkably, RF $\geqslant 50 \mathrm{U} / \mathrm{ml}$ and anti-CCP showed similar sensitivity and high specificity for RA, but overlapped considerably. Anti-RA33 was less specific and did not correlate with RF or anti-CCP. Among patients with RA, 72\% showed at least one of these three autoantibodies, compared with $15 \%$ of non-RA patients. RF $\geqslant 50 \mathrm{U} / \mathrm{ml}$ and anti-CCP were predictors of erosive disease, whereas anti-RA33 was associated with mild disease.

Conclusions: Stepwise autoantibody testing in early inflammatory joint disease, starting with RF, followed by anti-CCP (in patients with RF $<50 \mathrm{U} / \mathrm{ml}$ ), and finally anti-RA33, should be used as a sensitive and effective strategy for distinguishing patients with RA at high risk for poor outcome.

$\mathrm{D}$ uring the past decade the therapeutic paradigms in rheumatoid arthritis (RA) have changed considerably. Evidence for the occurrence of joint erosions within the first few months in the course of RA has led to recognition of the importance of early institution of disease modifying antirheumatic drugs (DMARDs), which can retard the progression of disability. ${ }^{1-3}$ Such advantage was shown in several early RA trials, which often included patients with symptom duration of $<1$ year. ${ }^{45}$ Furthermore, it has been demonstrated that such treatment started within only 3 months of symptom onset is more efficient than even short delays of treatment, with a continuing beneficial effect in long term follow up. ${ }^{67}$

However, early treatment of RA requires reliable differential diagnosis, which may be difficult in the initial stage of inflammatory joint disorders. The clinical presentation of RA and other arthritides early in their course is not always characteristic; moreover, classification criteria for RA, developed in established disease, ${ }^{8}$ are frequently not fulfilled in the early stages. ${ }^{90}$ Thus, instead of searching for fulfilment of classification criteria among early inflammatory joint diseases, it remains important to predict joint destruction, which primarily relates to RA, as early in the disease course as possible.

Among the seven classification criteria of the American College of Rheumatology (ACR) for RA, rheumatoid factor (RF) is the only serological marker. ${ }^{8} \mathrm{RF}$ has been shown to be associated with unfavourable outcome for joint destruction and disability, ${ }^{11}$ particularly when present in high titre. ${ }^{12}$ However, RF is often negative or present at a low titre in the early disease stages. Among several new autoantibodies described in recent years in patients with RA, anti-cyclic citrullinated peptide antibodies (anti-CCP), which bind antigenic determinants containing the unusual amino acid citrulline, seem to be the most promising. ${ }^{13}$ Such determinants have been found in several proteins, including filaggrin, fibrinogen/fibrin, and vimentin. ${ }^{14}{ }^{15}$ Another autoantibody of potential diagnostic value is anti-RA33, which is directed to the heterogeneous nuclear ribonucleoprotein A2; although less specific for RA than anti-CCP, anti-RA33 may nevertheless prove helpful for the diagnosis of RA. ${ }^{16}$

Production of RF, anti-CCP, and anti-RA33 may occur early in the disease and can even precede the development of clinical manifestations in RA by several years. ${ }^{17-19}$ Recent studies have described the occurrence of anti-CCP in 41-68\% of patients with early RA. ${ }^{20-26}$ However, up to $90 \%$ of anti-CCP positive patients were also positive for $\mathrm{RF}^{202124}$ and Cooccurrence of both antibodies was not more specific for RA than occurrence of either antibody alone. ${ }^{25} 27$

Given this frequent concurrence of RF and anti-CCP as well as the economic impact of broad anti-CCP testing, we investigated if autoantibody profiling by sequential testing at first presentation might have diagnostic and prognostic value in differentiating RA from other arthritic disorders in an inception cohort of patients with very early inflammatory joint disease.

Abbreviations: ACR, American College of Rheumatology; anti-CCP, anti-cyclic citrullinated peptide antibodies; DAS28, 28 joint count Disease Activity Score; DMARDs, disease modifying antirheumatic drugs; PPV, positive predictive value; RA, rheumatoid arthritis; ROC, receiver operating characteristics; RF, rheumatoid factor 


\section{PATIENTS AND METHODS Patients}

An inception cohort of patients recruited within the Austrian Early Arthritis Action was followed up prospectively. Details of this patient group have been described elsewhere. ${ }^{10} 2829$ Briefly, patients were included in this study if they fulfilled the following criteria: symptom duration $<3$ months, nontraumatic synovitis of at least one joint, and erythrocyte sedimentation rate $>20 \mathrm{~mm} / \mathrm{lst} \mathrm{h}$ or $\mathrm{C}$ reactive protein $>5 \mathrm{mg} / \mathrm{l}$. Informed consent was obtained from all patients enrolled. The study was approved by the local ethical committee and followed the Good Clinical PracticeInternational Congress of Harmonisation guidelines. The first 200 consecutive patients who had follow up examinations over at least 6 months were included in the present analysis.

Initial preliminary diagnoses were based on the appropriate diagnostic or classification criteria and clinical judgment. When such a preliminary diagnosis could not be established, the disease was classified as undifferentiated arthritis. All diagnoses were ascertained clinically in the course of the disease and/or by chart review after 6 or 12 months by an experienced rheumatologist (KPM). RA was diagnosed in patients with persistent arthritis of more than 12 weeks, if the ACR criteria for RA were fulfilled at baseline or cumulatively during the first year of follow up, or both. ${ }^{30-32}$

\section{Detection of autoantibodies}

RF was measured by nephelometry; a level of $>20 \mathrm{U} / \mathrm{ml}$ was considered positive. Anti-CCP antibodies were measured by enzyme linked immunosorbent assay (ELISA; Axis Shields Diagnostics, Dundee, UK) and considered positive above a cut off value of 5 arbitrary units as suggested by the manufacturer. Anti-RA33 was assessed by immunoblotting using recombinant and natural antigens as described previously. ${ }^{33}$ Antibodies were determined at first visitthat is, in patients with $<3$ months of symptom duration and additionally at 6 and 12 months from baseline, and every 6 months thereafter, when applicable.

\section{Clinical and radiographic assessments}

Clinical and laboratory data were collected every 3 months according to the core set of disease activity measures for RA. ${ }^{35}$ The 28 joint count disease activity score (DAS28) was calculated as a measure of RA activity. ${ }^{36}$ In patients with RA, initial and yearly follow up radiographs of hands and feet, blinded for group and sequence, were assessed by a rheumatologist (KPM) and a radiologist (MU). To account for any fortuitous findings of singular erosions, only patients with at least two erosions in at least two different joints were classified as erosive. Erosions were defined as follows: presence of at least two unequivocal lesions on any hand or foot joint, except the distal interphalangeal joint, with unequivocal cortical break of at least $1 \mathrm{~mm}$ in width in one of the erosions or, if the erosion or the cortical break was smaller, presence of at least two such lesions on different joints. In addition, radiographs were scored according to the Larsen method on 42 joints in the hands and feet: firstly, films were scored using the traditional Larsen scoring with 0 (normal) to 5 (mutilating changes) for each individual joint ${ }^{37}$; secondly, grade 1 scores were abandoned and the total scores recalculated. ${ }^{38}$ Only the latter modified Larsen score will be shown in our analyses. Precision of assessment was ascertained by reassessing a subset of 40 randomly chosen radiographs: the correlation coefficient between both assessments was 0.86 (95\% confidence interval 0.805 to 0.906).

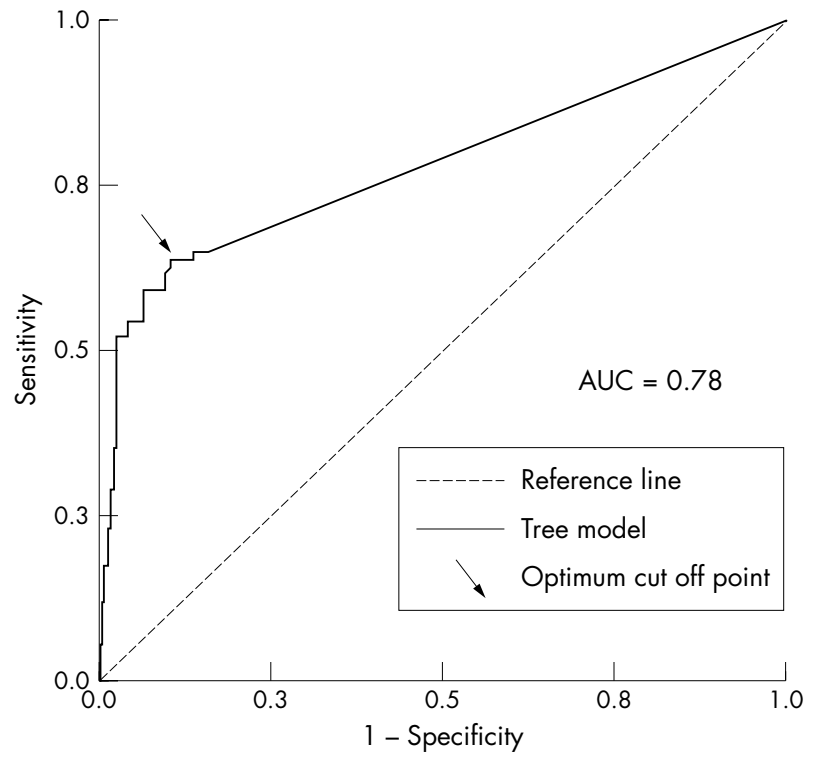

Figure 1 ROC curve for the tree based model. Using a computer based tree model we obtained the optimum cut off value for RF above which determining anti-CCP and/or anti-RA33 would add no significant

benefit in identifying patients with RA. This value was found at $49.75 \mathrm{IU} /$ I (indicated by an arrow), and RF values $\geqslant 50 \mathrm{U} / \mathrm{ml}$ were subsequently called "high titre" RF. The ROC curve shows an area under the curve for this model of 0.78 .

\section{Statistical analysis}

SPSS statistical software was used for statistical analysis (SPSS Inc, Chicago, IL). The reported $\mathrm{p}$ values are the results of two sided tests. A $p$ value $\leqslant 0.05$ was considered significant. To determine the added diagnostic value of testing for anti-CCP and anti-RA33 in addition to RF, as opposed to RF testing alone, for differentiation of RA $v$ nonRA, we used a tree based approach by taking into account the continuous RF levels and the corresponding dichotomous anti-CCP and anti-RA33 status (0 for negative, 1 for positive test). The RF level with the highest accuracy (sum = sensitivity plus specificity), determined from a receiver operating characteristics (ROC) curve, ${ }^{39}$ was used as a candidate cut off level that would split samples into two clusters: above this candidate RF level, the additional information from anti-CCP and/or anti-RA33 testing would not add significant predictive value in distinguishing RA from non-RA; below this level, a positive anti-CCP and/or antiRA33 test would be of further diagnostic value. The area under the ROC curve for the tree based model was computed, indicating, for a randomly chosen patient with RA and a nonRA control patient, the probability that the patient with RA will have a higher test value than the control; a value of 0.5 indicates no discrimination and a value of 1 perfect discrimination.

The presence of erosions in patients with RA with at least 1 year's follow up and complete sets of radiographs of hands and feet was used as the major outcome variable (erosive $v$ non-erosive disease) for determination of the prognostic value of autoantibodies at baseline. In addition, changes from baseline in Larsen scores were analysed in patient groups with different autoantibody profiles at baseline and analysed by employing the summary measures approach of Matthews et al. ${ }^{40}$ For Larsen scores the regression of score over time was computed for each patient and the resulting regression coefficients were considered to summarise individual progression over time. Differences in regression coefficients between the groups were non-parametrically tested using the 
Table 1 Diagnostic value of RF, anti-CCP and anti-RA33 autoantibodies. Data in the overall patient population

\begin{tabular}{llllll}
\hline Autoantibodies & $\begin{array}{l}\text { RA } \\
(\mathbf{n = 1 0 2 )}\end{array}$ & $\begin{array}{l}\text { Non-RA } \\
(\mathbf{n = 9 8})\end{array}$ & $\begin{array}{l}\text { Sensitivity } \\
(\%)\end{array}$ & $\begin{array}{l}\text { Specificity } \\
(\%)\end{array}$ & $\begin{array}{l}\text { PPV } \\
(\%)\end{array}$ \\
\hline RF $(>20 \mathrm{U} / \mathrm{ml})(\mathrm{n})$ & 56 & 11 & 55 & 89 & 84 \\
High titre RF $\geqslant 50 \mathrm{U} / \mathrm{ml})(\mathrm{n})$ & 46 & 4 & 45 & 96 & 92 \\
Anti-CCP (n) & 42 & 2 & 41 & 98 & 96 \\
Anti-RA33 (n) & 29 & 10 & 28 & 90 & 74 \\
\hline
\end{tabular}

PPV, positive predictive value.

High titre RF ( $\geqslant 50 \mathrm{U} / \mathrm{ml}$ ) and anti-CCP both showed high specificity and comparable sensitivity, whereas low titre

$\mathrm{RF}$ occurred with similar frequency in the RA and in the non-RA group.

Wilcoxon ranked sum test $\left(\mathrm{p}_{\mathrm{sm}}\right)$. Binary variables were analysed using the $\chi^{2}$ test $(p)$.

\section{RESULTS}

\section{Diagnoses at baseline and after follow up}

Among the 200 patients enrolled in this study, 75 patients had at first visit a preliminary diagnosis of RA, with 35 of them fulfilling the ACR criteria for RA at baseline. After 1 year 102 patients had a final diagnosis of RA and all fulfilled the ACR criteria within the first year. As soon as RA was suspected, treatment was started with traditional DMARDs. Among the 98 non-RA patients, 37 were finally diagnosed as undifferentiated arthritis, 36 as reactive arthritis, and 25 had other diagnoses. For further analyses, the 98 non-RA patients were seen as one group.

Patients with RA were slightly older at symptom onset, with a mean age of 50 (range 18-83) years as opposed to 43 (range 18-87) years in non-RA patients. The proportion of female patients, median symptom duration until first presentation in clinics, and disease activity scores were similar for patients with RA and non-RA patients. Median follow up time for patients with RA was 27 months (range 648 ), and for non-RA patients 18 months (range 6-48).

\section{Determination of the optimum cut off value for RF in a tree based model, and diagnostic value of RF, anti- CCP, and anti-RA33}

$\mathrm{RF}$, anti-CCP, and anti-RA33 were measured at baseline in all patients. To determine the added diagnostic value of antiCCP and anti-RA33 as compared with RF alone, the data were entered into a tree based model, which found a candidate cut off level for RF at $49.75 \mathrm{U} / \mathrm{ml}$ as deduced from an ROC curve (fig 1): only below this RF level, would a positive anti-CCP and/or anti-RA33 test add significant further diagnostic value. RF values $\geqslant 50 \mathrm{U} / \mathrm{ml}$ will be referred to as "high titre" RF.

Based on this finding sensitivity, specificity, and positive predictive values (PPVs) of total RF (>20 U/ml), high titre RF $(\geqslant 50 \mathrm{U} / \mathrm{ml})$, anti-CCP, and anti-RA33 were calculated (table 1): RF $>20 \mathrm{U} / \mathrm{ml}$ was present in $55 \%$ of patients with RA and in $11 \%$ of non-RA patients, resulting in a specificity of $89 \%$. High titre RF, however, occurred in $45 \%$ of patients with

Table 2 Diagnostic value of RF, anti-CCP and anti-RA33 autoantibodies. Anti-CCP and antiRA33 in the subgroup of patients with negative or low titre $\operatorname{RF}(<50 \mathrm{U} / \mathrm{ml})$

\begin{tabular}{lll}
\hline Autoantibodies & $\begin{array}{l}\text { RA } \\
(\mathbf{n}=56)\end{array}$ & $\begin{array}{l}\text { Non-RA } \\
(\mathbf{n}=94)\end{array}$ \\
\hline Anti-CCP (n) & 14 & 2 \\
Anti-RA33 (n) & 14 & 9 \\
Both antibodies (n) & 1 & 0 \\
\hline
\end{tabular}

RA but in only $4 \%$ of non-RA patients, while "low titre" RF $(<50 \mathrm{U} / \mathrm{ml})$ was detected with similar frequency in both groups $(10 \%$ and $7 \%$, respectively) and therefore of little diagnostic value. Therefore in subsequent analyses patients with negative or low titre RF were grouped together. For antiCCP a sensitivity of $41 \%$ and a very high specificity of $98 \%$ was found, which was remarkably similar to the values obtained for high titre RF. The resulting PPVs were 92\% for high titre RF and 96\% for anti-CCP. Compared with these two antibodies, anti-RA33 was less sensitive $(28 \%)$ and less specific $(90 \%)$, resulting in a PPV of $74 \%$. It is noteworthy, that while high titre RF and anti-CCP overlapped considerably, with $28 \%$ of patients with early RA showing both antibodies $(\mathrm{p}<0.0001)$, anti-RA33 was not associated with either antibody. Importantly, anti-RA33 and anti-CCP occurred with identical frequencies (14\%) in patients with low titre or negative RF, with only one of the 28 patients being positive for both specificities (table 2 ).

\section{Prognostic value of autoantibodies: correlation with erosive disease}

Complete $x$ ray sets were available from 66 patients with RA. Unfortunately, films of the remaining 36 patients were not available for analysis owing to logistic reasons. However, baseline values of these patients did not differ significantly from the values of patients available for analysis (data not

Table 3 Prognostic value of autoantibodies for development of erosive disease in patients with RA. High titre RF, anti-CCP, and anti-RA33 in patients with RA with erosive and non-erosive disease

\begin{tabular}{lllll}
\hline & $\begin{array}{l}\text { Erosive } \\
(\mathbf{n = 3 6 )}\end{array}$ & $\begin{array}{l}\text { Non- } \\
\text { erosive } \\
(\mathbf{n = 3 0 )}\end{array}$ & $\begin{array}{l}\text { PPV } \\
(\%)\end{array}$ & p Value \\
\hline Follow up time (months), & $36(12-48)$ & $30(12-48)$ & & \\
median (range) & & & 78 & 0.002 \\
High titre RF (n) & 21 & 6 & 88 & $<0.001$ \\
Anti-CCP (n) & 22 & 3 & 61 & 0.51 \\
Anti-RA33 (n) & 11 & 7 & & \\
\hline
\end{tabular}

Table 4 Prognostic value of autoantibodies for development of erosive disease in patients with RA. Anti-CCP and anti-RA33 in the subgroup of patients with negative or low titre $\mathrm{RF}(<50 \mathrm{U} / \mathrm{ml})$

\begin{tabular}{lll}
\hline Antibodies & $\begin{array}{l}\text { Erosive } \\
(\mathbf{n}=15)\end{array}$ & $\begin{array}{l}\text { Non-erosive } \\
(\mathbf{n}=\mathbf{2 4})\end{array}$ \\
\hline Anti-CCP (n) & 7 & 2 \\
Anti-RA33 (n) & 3 & 6 \\
Both (n) & 1 & 0 \\
\hline
\end{tabular}



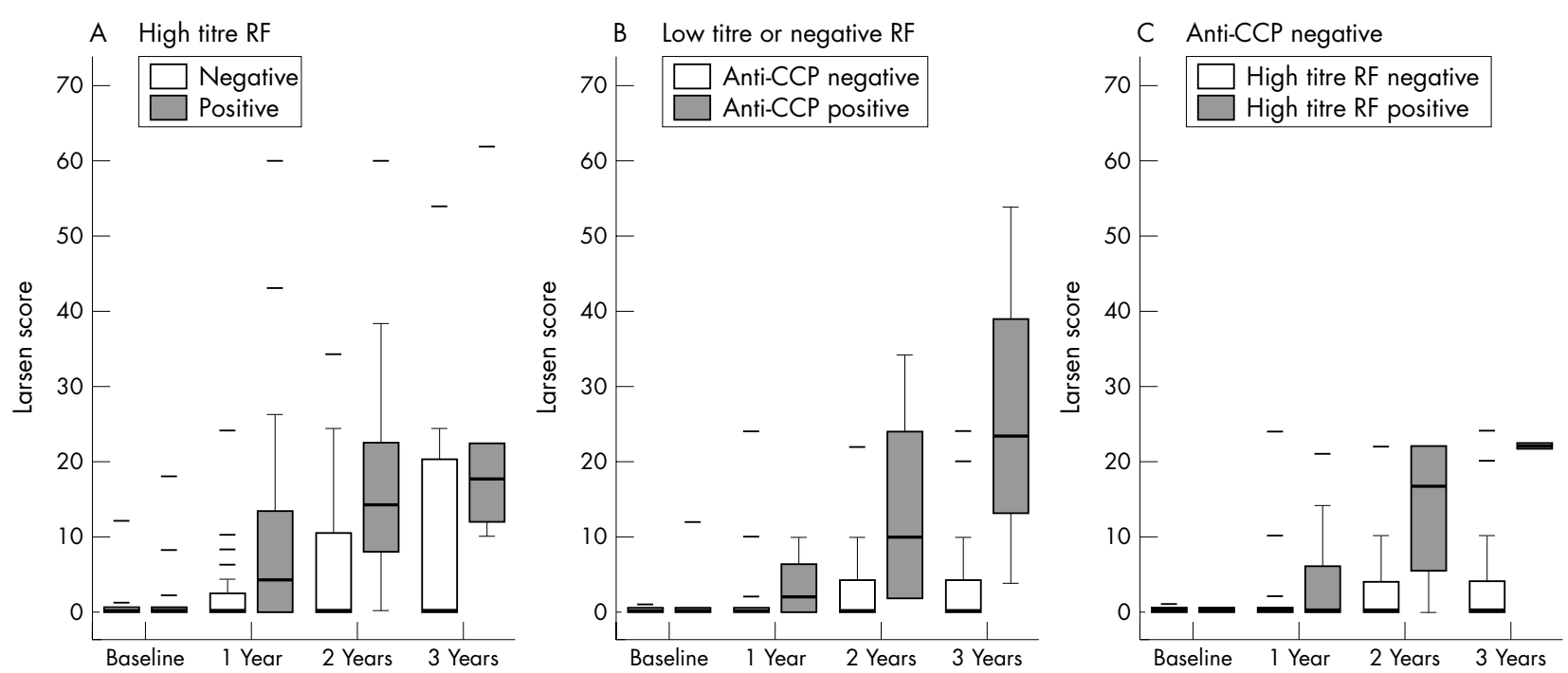

Figure 2 High titre RF and anti-CCP are associated with rapid radiographic progression of RA. Box plots showing the difference in Larsen scores (grade 1 abandoned) in (A) patients with RA with high titre RF $v$ low titre or negative RF; (B) patients with RA with low titre or negative RF, positive or negative for anti-CCP; and (C) anti-CCP negative patients with RA with high titre RF $v$ low titre or negative RF. The box shows median values and 25th/ 75th centiles. $\mathrm{P}_{\mathrm{sm}}$ values indicate differences in regression coefficients between the groups. Baseline values were similar in all groups, but Larsen score progression was significantly higher in patients with high titre RF than in patients with low titre or negative RF, and this both in the overall RA population $\left(p_{s m}<0.0001\right.$; fig 2A), and also in the subpopulation of anti-CCP negative patients $\left(p_{s m}=0.0014\right.$; fig $\left.2 C\right)$; a significant difference in progression was also seen between anti-CCP positive and anti-CCP negative patients in the subpopulation of patients with low titre or negative RF $\left(p_{s m}=0.038\right.$; fig $\left.2 B\right)$.

shown). After a median follow up time of more than 2 years, $36 / 66(55 \%)$ patients had erosive disease, but only $4 / 66(6 \%)$ had erosions already at the first visit. The initial distribution of DMARDs was similar in patients with erosive and nonerosive disease. However, DMARD switches were significantly more frequent in patients who developed erosive disease. High titre RF and anti-CCP were significantly associated with an increased risk of developing erosions as shown by PPVs of $78 \%$ for RF and $88 \%$ for CCP (table 3 ). In contrast, anti-RA33 was similarly distributed among the erosive and the non-erosive group and therefore not associated with erosive disease (tables 3 and 4).

In predicting erosive disease in patients with RA with low titre or negative RF, anti-CCP appeared to be of particular value (table 4): 15 patients of this group developed bone erosions and seven of them were anti-CCP positive at first

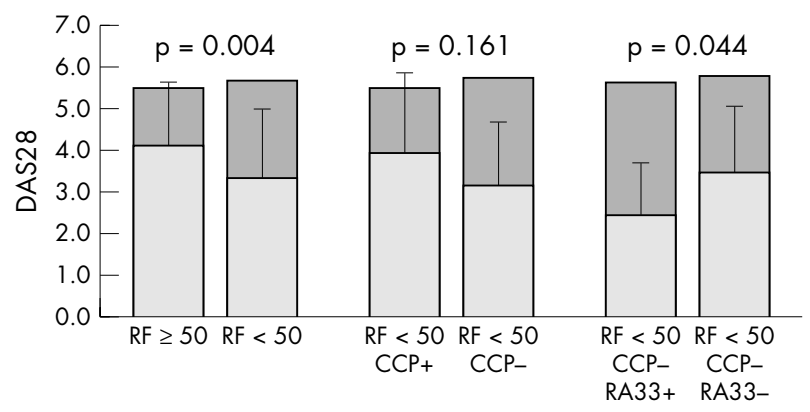

Figure 3 Prognostic value of autoantibodies for predicting improvement of disease activity. Baseline disease activity (DAS28) was similar in all patient groups (dark grey columns). At the study end point, DAS28 (light grey columns) was significantly lower in patients with RF $<50 \mathrm{U} / \mathrm{ml}$ than in patients with high titre RF. In patients with $\mathrm{RF}<50 \mathrm{U} /$ $\mathrm{ml}$ the difference between anti-CCP positive and anti-CCP negative patients was not significant. DAS28 in anti-RA33 positive patients was markedly lower than in high titre RF or anti-CCP positive patients and even significantly lower than in patients negative for all three autoantibodies. p Values represent the difference in DAS28 at study end point between the autoantibody positive versus negative group. visit, while among the 24 non-erosive patients only two showed this antibody $(\mathrm{p}=0.006)$.

Mean Larsen scores at baseline were similar in all groups, irrespectively of their autoantibody status (fig 2). However, Larsen scores were significantly higher in high titre RF patients than in patients with low titre or negative RF $\left(\mathrm{p}_{\mathrm{sm}}<0.0001\right.$, fig $\left.2 \mathrm{~A}\right)$; the same was found for anti-CCP positive versus anti-CCP negative patients (data not shown). Importantly, within the subgroup of patients with low titre or negative RF, anti-CCP positive patients showed significantly more rapid radiographic progression $\left(\mathrm{p}_{\mathrm{sm}}=0.038\right.$, fig $\left.2 \mathrm{~B}\right)$. To evaluate the independent value of RF as predictive marker for radiographic progression, we additionally analysed the subgroup of anti-CCP negative patients: again, patients with high titre RF showed significantly higher Larsen scores $\left(p_{s m}=0.0014\right.$, fig $\left.2 C\right)$. Thus, the slope of progression of joint destruction was much steeper in patients presenting with high titre RF or anti-CCP, or both, at baseline than in those negative for these autoantibodies.

\section{Prognostic value of autoantibodies: correlation with disease activity}

Disease activity at baseline (as measured by DAS28) was similar in all patients, irrespective of the antibody status (fig 3). However, improvement was significantly better in patients with low titre or negative RF than in patients with high titre RF $(p=0.004)$. Among patients with RF $<50 \mathrm{U} / \mathrm{ml}$, the anti-CCP positive patients showed higher disease activity than anti-CCP negative patients, but the difference did not reach significance, presumably owing to the relatively small number of patients in this group. Anti-RA33 positive patients, on the other hand, improved when treated with DMARDs from baseline to a significantly higher degree than RF or anti-CCP positive patients. Noteworthy, improvement in anti-RA33 positive patients was even better than in patients negative for all three autoantibodies $(p=0.044)$. Thus, anti-RA33 (when occurring alone) appears to characterise patients with mild disease and a more favourable outcome. 


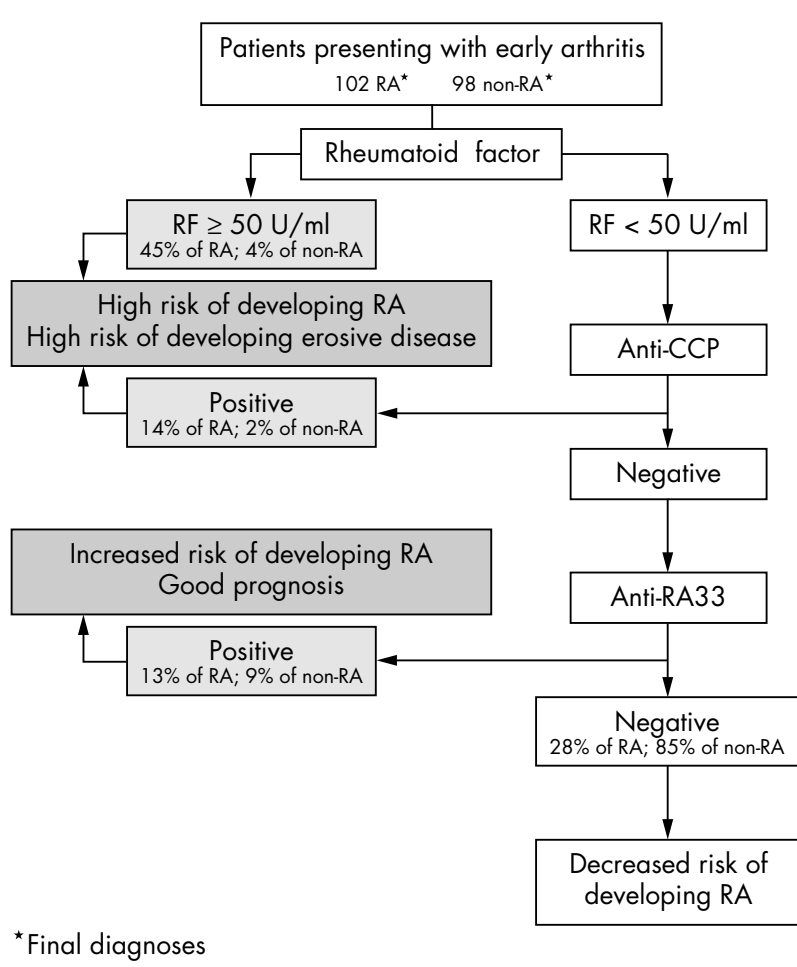

Figure 4 Decision tree to determine risk of RA and erosive disease in patients with early arthritis. All patients with early arthritis are tested for RF. High titre RF ( $\geqslant 50 \mathrm{U} / \mathrm{ml})$ is highly predictive for the diagnosis of RA and for developing erosive disease, and there is no benefit from determining additional autoantibodies. In patients with low titre or negative RF, anti-CCP determination helps to identify additional patients with RA at high risk of developing erosive disease. In patients negative for RF and anti-CCP, anti-RA33 testing may allow identification of patients with a more favourable outcome. Percentages shown correspond to the total numbers of patients with RA and non-RA patients.

\section{Development of an algorithm for serological testing}

The data obtained suggested stepwise testing for the three autoantibodies as an efficient strategy for identifying patients with early RA at high risk for developing erosive disease (fig 4). Because $45 \%$ of the 102 patients with RA and only $4 \%$ of the 98 non-RA patients had high titre RF there would have been no further need to test these patients for anti-CCP or anti-RA33 in order to assess the diagnosis of RA and the risk of an unfavourable outcome. Among the 150 remaining patients, however, anti-CCP testing was of great diagnostic benefit because 14 additional patients with RA could be identified, with only two non-RA patients being positive. This resulted in 59\% of patients with RA and $6 \%$ of non-RA patients positive for high titre RF or anti-CCP, or both. Moreover, patients with RA showing either of the two antibodies had a significantly increased risk for development of erosive disease. Among the 134 patients (42 RA and 92 non-RA) negative for these two antibodies, anti-RA33 testing disclosed an additional 13 patients with RA but was also positive in nine non-RA patients.

In summary, only $28 \%$ of patients with RA were negative for all three autoantibodies compared with $85 \%$ of nonpatients with RA. This model of stepwise testing for three different autoantibodies therefore yields an overall sensitivity of $72 \%$ for the diagnosis of RA in patients with very early inflammatory joint disease.

\section{DISCUSSION}

The ability to identify those patients who will develop progressive, erosive disease remains the major objective in early arthritis because these patients may particularly benefit from early, more intensive treatment. Patients treated with DMARDs within the first few weeks to months after onset of symptoms have a longlasting benefit, with their disease progression markedly retarded compared with patients whose treatment is delayed..$^{1-7}$ Because only patients with inflammatory joint disease of $<3$ months' symptom duration were studied here, we were able to investigate the autoantibody profiles within only a few weeks from onset of clinically apparent synovitis both in patients with RA and in an inherent control group meeting the same inclusion criteria, but developing other forms of inflammatory arthritis.

The proposed diagnostic algorithm for autoantibody testing in patients with very early inflammatory joint disease (fig 4) is not only helpful in establishing a diagnosis of RA in more than $70 \%$ of the patients but also allows definition of patients at increased risk for developing erosive disease. The first step of this algorithm, the presence of high titre RF, conformed with the diagnosis of RA in $45 \%$ of the patients with RA and showed high disease specificity, which was surprisingly similar to that found for anti-CCP. While the high specificity of anti-CCP is undisputed, RF is often considered a reasonably sensitive but relatively non-specific marker of RA which-as the data clearly demonstrate-depends on the choice of the cut off level. The optimum cut off level for RF calculated in the tree based model was in very good agreement with previous reports showing that only RF $\geqslant 50 \mathrm{U} / \mathrm{ml}$ was significantly associated with RA. ${ }^{12} 2527$ Together, these findings suggest that redefinition of RF positivity for RA should be considered because RF $<50 \mathrm{U} / \mathrm{ml}$ seems to be of little, if any, diagnostic usefulness. Thus, in an early arthritis clinic only patients with high titre RF should be considered RF positive. This justifies the proposed stepwise approach to autoantibody determination, which is also in line with previous statements that RF and anti-CCP frequently concur $^{20} 21$ and that the presence of both antibodies is not more specific for RA than either antibody alone. ${ }^{25}{ }^{27}$ Because also the prognostic values of high titre RF and anti-CCP for erosive disease were comparable, testing patients with high titre RF additionally for anti-CCP seems to be of limited diagnostic benefit. However, when RF is of low titre or negative, anti-CCP is an extremely helpful diagnostic marker being not only highly specific for RA but also strongly associated with erosive disease, which is in full agreement with other reports. ${ }^{25-27}$

Overall, it should be noted that despite the excellent performance of high titre RF, anti-CCP proved slightly better, both for disease specificity and prognostic value. Thus, if there were no financial restrictions it might be more advisable to determine anti-CCP first and RF additionally in anti-CCP negative patients, or ideally, both antibodies in parallel. Considering costs, even though anti-CCP testing is considerably more expensive than RF determination, one might argue that if an anti-CCP result is positive then follow up testing would not necessarily be required.

Taken together, for now the proposed algorithm may help to establish an effective diagnosis and prognosis in the majority of patients with very early inflammatory joint disease, which needs to be confirmed in other cohorts of patients with very early arthritis. Because both high titre RF and anti-CCP are strong predictors of erosive disease, therapeutic strategies in patients showing such antibodies may need to be more aggressive, including use of the most efficient compounds available today. ${ }^{41-43}$ Anti-RA33, on the other hand, despite its limited specificity, may be useful in patients negative for high titre RF and anti-CCP, allowing identification of patients with a good prognosis who will respond well to treatment with DMARDs. Thus, autoantibody signatures convey diagnostic and prognostic insights that 
may allow appropriate therapeutic strategies to be designed even at the first visit, a time point most challenging in the course of RA.

\section{ACKNOWLEDGEMENTS}

We are very grateful for the expert technical assistance of Hannelore Hiesberger and Elisabeth Hoefler.

This work was supported by CeMM, Centre for Molecular Medicine of the Austrian Academy of Sciences.

\section{Authors' affiliations}

V P K Nell, K P Machold, T A Stamm, J S Smolen, G Steiner, Division of Rheumatology, Department of Internal Medicine III, Medical University of Vienna, Austria

G Eberl, J S Smolen, Second Department of Medicine, Lainz Hospital, Vienna, Austria

H Heinzl, Department of Medical Computer Sciences, Medical University of Vienna, Austria

M Uffmann, Department of Radiology, Medical University of Vienna,

Austria

J S Smolen, G Steiner, Ludwig Boltzmann-Institute for Rheumatology,

Vienna, Austria

\section{REFERENCES}

1 O'Dell JR. Therapeutic strategies for rheumatoid arthritis. N Engl J Med 2004;350:2591-602.

2 Smolen JS, Aletaha D, Machold KP. Therapeutic strategies in early rheumatoid arthritis. Best Pract Res Clin Rheumatol 2005;19:163-77.

3 Quinn MA, Emery P. Window of opportunity in early rheumatoid arthritis: possibility of altering the disease process with early intervention. Clin Exp Rheumatol 2003;21(suppl 31):S154-7.

4 van der Heide A, Jacobs JW, Biilsma JW, Heurkens AH, Booma-Frankfort C, van der Veen MJ, et al. The effectiveness of early treatment with "second-line" antirheumatic drugs. A randomized, controlled trial. Ann Intern Med 1996; 124:699-707.

5 Mottonen $T$, Hannonen $P$, Leirisalo-Repo M, Nissila M, Kautiainen $\mathrm{H}$, Korpela $M$, et al. Comparison of combination therapy with single-drug therapy in early rheumatoid arthritis: a randomized trial. FIN-RACo trial group. Lancet 1999;353:1568-73.

6 van Aken J, Lard LR, le Cessie S, Hazes JM, Breedveld FC, Huizinga TW Radiological outcome after four years of early versus delayed treatment strategy in patients with recent onset rheumatoid arthritis. Ann Rheum Dis 2004; 63:274-9

7 Nell VP, Machold KP, Eberl G, Stamm TA, Uffmann M, Smolen JS. Benefit of very early referral and very early therapy with disease-modifying antirheumatic drugs in patients with early rheumatoid arthritis. Rheumatology (Oxford) 2004;43:906-14

8 Arnett FC, Edworthy SM, Bloch DA, McShane DJ, Fries JF, Cooper NS, et al. The American Rheumatism Association 1987 revised criteria for the classification of rheumatoid arthritis. Arthritis Rheum 1988;31:315-24.

9 Symmons DP, Hazes JM, Silman AJ. Cases of early inflammatory polyarthritis should not be classified as having rheumatoid arthritis. J Rheumatol 2003;30:902-4

10 Machold KP, Stamm TA, Eberl GJ, Nell VK, Dunky A, Uffmann M, et al. Very recent onset arthritis-clinical, laboratory, and radiological findings during the first year of disease. J Rheumatol 2002;29:2278-87.

11 Scott DL, Symmons DP, Coulton BL, Popert AJ. Long-term outcome of treating rheumatoid arthritis: results after 20 years. Lancet 1987;i: $1108-11$

12 Sinclair D, Hull RG. Why do general practitioners request rheumatoid factor? A study of symptoms, requesting patterns and patient outcome. Ann Clin Biochem 2003;40(Pt 2):131-7.

13 Schellekens GA, de Jong BA, van den Hoogen FH, van de Putte LB, van Venrooij WJ. Citrulline is an essential constituent of antigenic determinants recognized by rheumatoid arthritis-specific autoantibodies. J Clin Invest 1998; 101:273-81

14 Sebbag M, Simon M, Vincent C, Masson-Bessiere C, Girbal E, Durieux JJ, et al. The antiperinuclear factor and the so-called antikeratin antibodies are the same rheumatoid arthritis-specific autoantibodies. J Clin Invest 1995; $95: 2672-9$

15 Vossenaar ER, Despres N, Lapointe E, van der Heijden A, Lora M, Senshu T, et al. Rheumatoid arthritis specific anti-Sa antibodies target citrullinated vimentin. Arthritis Res Ther 2004:6:R142-50.

16 Steiner G, Smolen J. Autoantibodies in rheumatoid arthritis and their clinical significance. Arthritis Res 2002;4(suppl 2):S1-5.

17 Aho K, Steiner G, Kurki P, Paimela L, Leirisalo-Repo M, Palosuo T, et al. AntiRA 33 as a marker antibody of rheumatoid arthritis in a Finnish population. Clin Exp Rheumatol 1993;11:645-7.

18 Aho K, von Essen R, Kurki P, Palosuo T, Heliovaara M. Antikeratin antibody and antiperinuclear factor as markers for subclinical rheumatoid disease process. J Rheumatol 1993;20:1278-81.
19 Rantapaa-Dahlqvist S, de Jong BA, Berglin E, Hallmans G, Wadell G, Stenlund $\mathrm{H}$, et al. Antibodies against cyclic citrullinated peptide and $\lg \mathrm{A}$ rheumatoid factor predict the development of rheumatoid arthritis. Arthritis Rheum 2003:48:2741-9.

20 Forslind K, Ahlmen M, Eberhardt K, Hafstrom I, Svensson B. BARFOT Study Group. Prediction of radiological outcome in early rheumatoid arthritis in clinical practice: role of antibodies to citrullinated peptides (anti-CCP), Ann Rheum Dis 2004;63:1090-5.

21 Kastbom A, Strandberg G, Lindroos A, Skogh T. Anti-CCP antibody test predicts the disease course during 3 years in early rheumatoid arthritis (the Swedish TIRA project). Ann Rheum Dis 2004;63:1085-9.

22 Soderlin MK, Kastbom A, Kautiainen H, Leirisalo-Repo M, Strandberg G, Skogh T. Antibodies against cyclic citrullinated peptide (CCP) and levels of cartilage oligomeric matrix protein (COMP) in very early arthritis: relation to diagnosis and disease activity. Scand J Rheumatol 2004;33:185-8.

23 Raza K, Breese M, Nightingale P, Kumar K, Potter T, Carruthers DM, et al. Predictive value of antibodies to cyclic citrullinated peptide in patients with very early inflammatory arthritis. J Rheumatol 2005;32:231-8.

24 Van Gaalen FA, Linn-Rasker SP, van Venrooii WJ, de Jong BA, Breedveld FC, Verweii $\mathrm{CL}$, et al. Autoantibodies to cyclic citrullinated peptides predict progression to rheumatoid arthritis in patients with undifferentiated arthritis: a prospective cohort study. Arthritis Rheum 2004;50:709-15.

25 Nielen MM, van der Horst AR, van Schaardenburg D, van der HorstBruinsma IE, van de Stadt RJ, Aarden L, et al. Antibodies to citrullinated human fibrinogen (ACF) have diagnostic and prognostic value in early arthritis. Ann Rheum Dis 2005;64:1 199-204.

26 Meyer O, Labarre C, Dougados M, Goupille P, Cantagrel A, Dubois A. Anticitrullinated protein/peptide antibody assays in early rheumatoid arthritis for predicting five year radiographic damage. Ann Rheum Dis 2003;62:120-6.

27 Jansen AL, van der Horst-Bruinsma I, van Schaardenburg D, van de Stadt R, de Koning M, Dijkmans BA. Rheumatoid factor and antibodies to cyclic citrullinated peptide differentiate rheumatoid arthritis from undifferentiated polyarthritis in patients with early arthritis. J Rheumatol 2002;29:2074-6.

28 Machold KP, Eberl G, Leeb BF, Nell V, Windisch B, Smolen JS. Early arthritis therapy: rationale and current approach. J Rheumatol Suppl 1998;53:13-19.

29 Machold KP, Nell VP, Stamm TA, Eberl G, Steiner G, Smolen JS. The Austrian Early Arthritis Registry. Clin Exp Rheumatol 2003;21(suppl 31):S113-17.

30 Harrison BJ, Symmons DP, Barrett EM, Silman AJ. The performance of the 1987 ARA classification criteria for rheumatoid arthritis in a population based cohort of patients with early inflammatory polyarthritis. American Rheumatism Association. J Rheumatol 1998:25:2324-30.

31 Aletaha D, Eberl G, Nell VP, Machold KP, Smolen JS. Practical progress in realisation of early diagnosis and treatment of patients with suspected rheumatoid arthritis: results from two matched questionnaires within three years. Ann Rheum Dis 2002:61:630-4.

32 Green M, Marzo-Ortega H, McGonagle D, Wakefield R, Proudman S, Conaghan $P$, et al. Persistence of mild, early inflammatory arthritis: the importance of disease duration, rheumatoid factor, and the shared epitope. Arthritis Rheum 1999;42:2184-8.

33 Fritsch R, Eselbock D, Skriner K, Jahn-Schmid B, Scheinecker C, Bohle B, et al. Characterization of autoreactive $T$ cells to the autoantigens heterogeneous nuclear ribonucleoprotein A2 (RA33) and filaggrin in patients with rheumatoid arthritis. J Immunol 2002; 169:1068-76.

34 Skriner K, Sommergruber WH, Tremmel V, Fischer I, Barta A, Smolen JS, et al. Anti-A2/RA33 autoantibodies are directed to the RNA binding region of the A2 protein of the heterogeneous nuclear ribonucleoprotein complex. Differential epitope recognition in rheumatoid arthritis, systemic lupus erythematosus, and mixed connective tissue disease. J Clin Invest 1997:100:127-35

35 Smolen JS. The work of the EULAR Standing committee on International Clinical Studies Including Therapeutic Trials (ESCISIT). Br J Rheumatol 1992;31:219-20.

36 Prevoo ML, van 't Hof MA, Kuper HH, van Leeuwen MA, van de Putte LB, van Riel PL. disease activity scores that include twenty-eight-joint counts. Development and validation in a prospective longitudinal study of patients with rheumatoid arthritis. Arthritis Rheum 1995;38:44-8.

37 Larsen A, Dale K, Eek M. Radiographic evaluation of rheumatoid arthritis and related conditions by standard reference films. Acta Radiol Diagn (Stockh) 1977; 18:481-91.

38 Kirwan JR. Using the Larsen index to assess radiographic progression in rheumatoid arthritis. J Rheumatol 2000;27:264-8.

39 Zweig MH, Campbell G. Receiver-operating characteristic (ROC) plots: a fundamental evaluation tool in clinical medicine. Clin Chem 1993:39:561-77.

40 Matthews JNS, Altman DG, Campbell MJ, Royston P. Analysis of serial measurements in medical research. BMJ 1990;300:230-5.

41 Grigor C, Capell H, Stirling A, McMahon AD, Lock P, Vallance R, et al. Effect of a treatment strategy of tight control for rheumatoid arthritis (the TICORA study): a single blind randomized controlled trial. Lancet 2004;364:263-9.

42 Smolen JS, Sokka T, Pincus T, Breedveld FC. A proposed treatment algorithm for rheumatoid arthritis: aggressive therapy, methotrexate, and quantitative measures. Clin Exp Rheumatol 2003;21(suppl 31):209-10.

43 De Vries-Bouwstra JK, Goekoop-Ruiterman YPM. Van Zeben D, Breedveld FC, Dijkmans BAC, Hazes JMW, et al. A comparison of clinical and radiological outcomes of four treatment strategies for early rheumatoid arthritis: results of the BEST trial [abstract], Ann Rheum Dis 2004;63/suppl 1):58. 